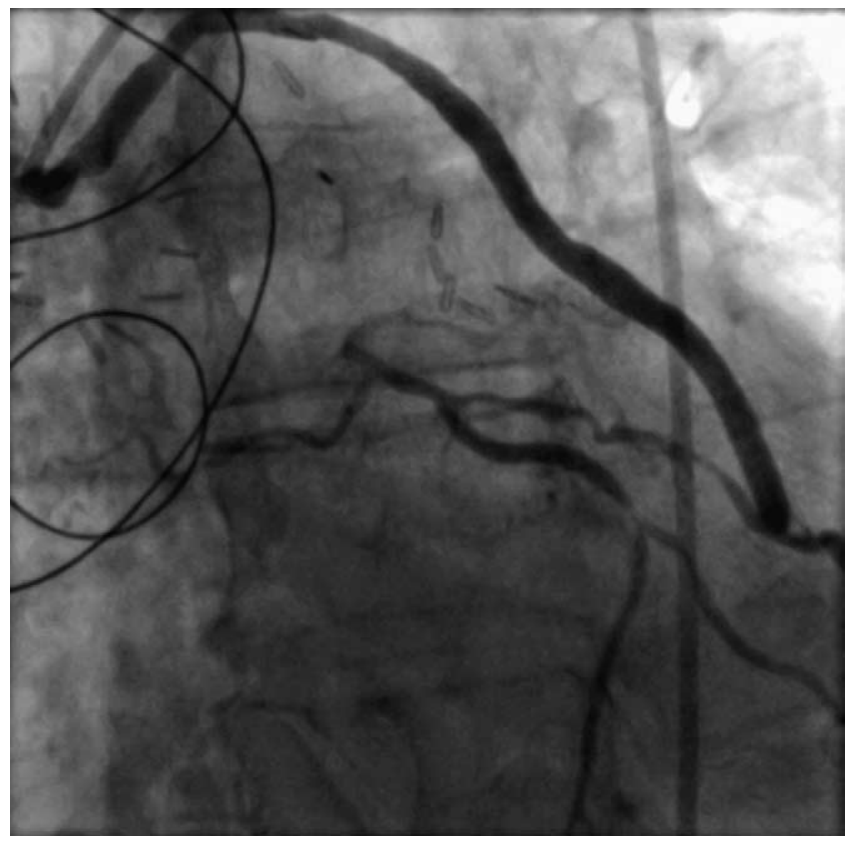

Figure 2. Intra-operative completion angiogram after percutaneous intervention with improved runoff in recruited collaterals.
A second unique advantage of the hybrid operating environment is in providing less-invasive therapeutic options. As in our patient, surgical graft revision would have required a second period of cardiopulmonary bypass and aortic clamping, and this was avoided by electing to perform a less-invasive percutaneous intervention. This resulted in a dramatic improvement in the graft flow and distal runoff with recruitment of collaterals and immediate resolution of the patient's mitral regurgitation. Moreover, the hybrid environment will undoubtedly lead to more liberal use of minimally invasive valve operations combined with percutaneous coronary interventions and combined surgical and percutaneous revascularization techniques. ${ }^{3}$

\section{References}

1. Byrne JG, Leacche M, Unic D, Rawn JD, Simon DI, Rogers CD, et al. Staged initial percutaneous coronary intervention followed by valve surgery ("hybrid approach") for patients with complex coronary and valve disease. J Am Coll Cardiol. 2005;45:14-8.

2. Goldman S, Zadina K, Moritiz T, Ovitt T, Sethi G, Copeland JG, et al. Long-term patency of saphenous vein and internal mammary artery grafts after coronary artery bypass surgery. $J$ Am Coll Cardiol. 2004; 44:2149-56.

3. Stahl K, Boyd WD, Vassiliades TA, Karamanoukian HL. Hybrid robotic coronary artery surgery and angioplasty in multivessel coronary artery disease. Ann Thorac Surg. 2002;74:S1358-62.

\title{
Aortobronchial fistula after aortic coartactation
}

\author{
Alfonso L. Quintana, MD, PhD, Esther Martínez Aguilar, MD, Alvaro Fernandez Heredero, MD, Vicente Riambau, MD, \\ Laura Paul, MD, and Francisco Acín, MD, PhD, Madrid, Spain
}

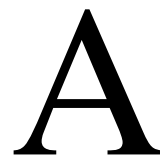

ortobronchial fistulas are an uncommon, but potentially fatal, complication of reconstructive surgery in the thoracic aorta.

Endovascular treatment is a less-invasive technique and represents an alternative for the treatment of this disease, particularly when conditions are inadequate for open surgery. We

\footnotetext{
From the Department of Angiology and Vascular Surgery, Getafe University Hospital, Madrid, Spain.

Received for publication July 3, 2005; revisions received Sept 30, 2005; accepted for publication Oct 7, 2005.

Address for reprints: Alfonso Lopez Quintana, MD, Department of Angiology and Vascular Surgery, Getafe University Hospital, Road Toledo 12,5 Km, Getafe, Madrid 28905, Spain (E-mail: esthermartinezaguilar@ hotmail.com).

J Thorac Cardiovasc Surg 2006;131:240-3

$0022-5223 / \$ 32.00$

Copyright $\odot 2006$ by The American Association for Thoracic Surgery doi:10.1016/j.jtcvs.2005.10.005
}

report a case of an aortobronchial fistula occurring 15 years after surgery for aortic coarctation that was resolved by use of endovascular treatment.

\section{Clinical Summary}

A 47-year-old man was transferred to our department because of an episode of massive hemoptysis not requiring recovery measures. The patient had undergone surgery for an aortic coarctation 15 years before. In the last year, he had had several minor episodes of hemoptysis for which he was being monitored by the pneumology department.

An initial bronchoscopic examination showed glandular openings that filled with blood in the medial wall of the right main bronchus and a slow sheet bleeding from both left lobes. The chest computed tomographic (CT) report suggested an aortobronchial fistula (Figure 1, A), and this diagnosis was confirmed by angiomagnetic resonance imaging.

The patient underwent surgery with general anesthesia and systemic heparinization. A left femoral approach and a $5 \mathrm{~F}$ inserter were used for arteriography, which showed a dilated 

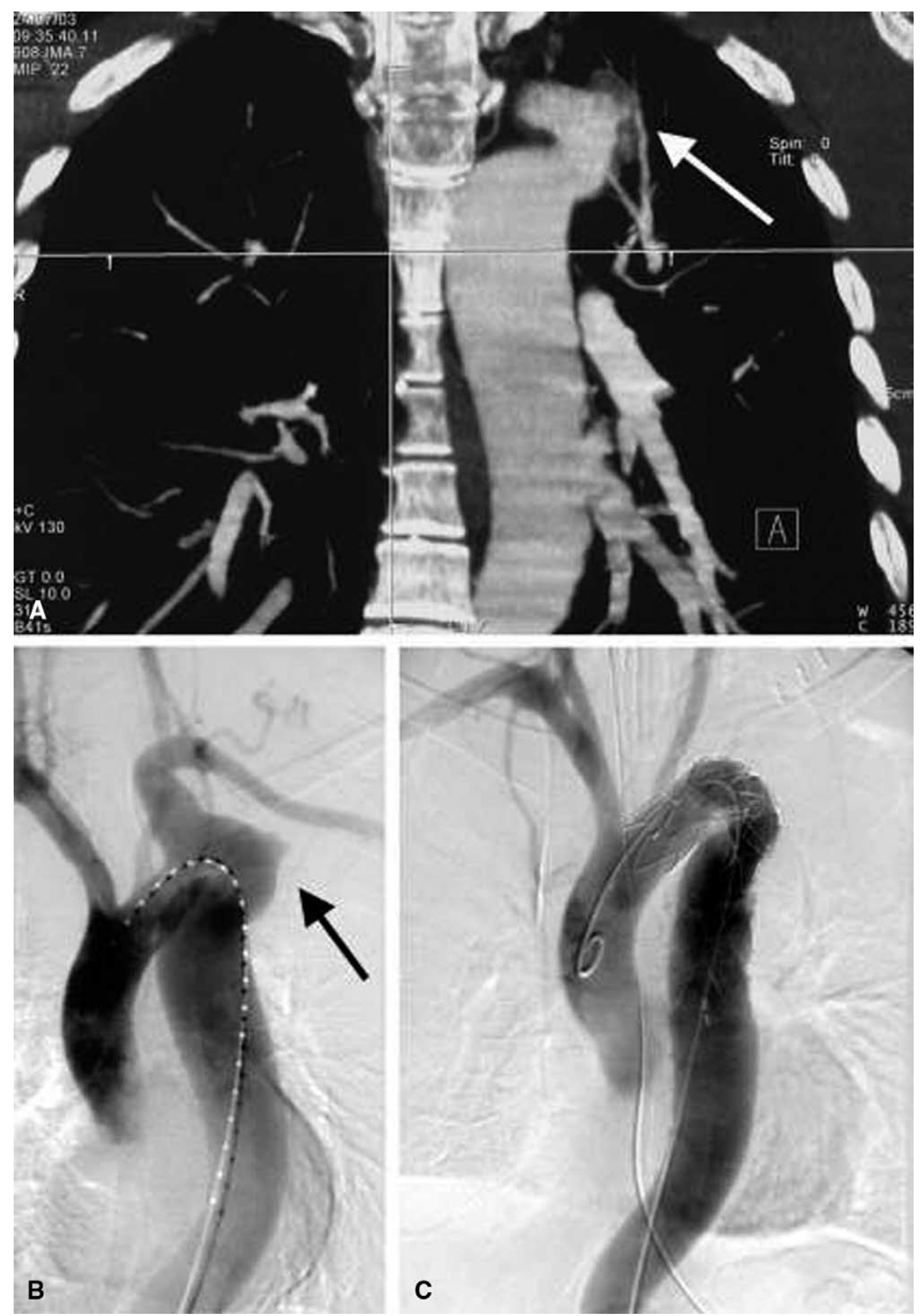

Figure 1. A, Computed tomography (CT) showing contrast extravasation at the aneurysmal dilatation. B, Arteriography showing dilatation of left subclavian artery, postcoarctation stenosis, and fraying of the posterior aspect of the aortic segment with aneurysmal dilatation distal to the subclavian artery. C, Control arteriography after stent implantation confirming exclusion of aneurysmal region and absence of endoleaks. 

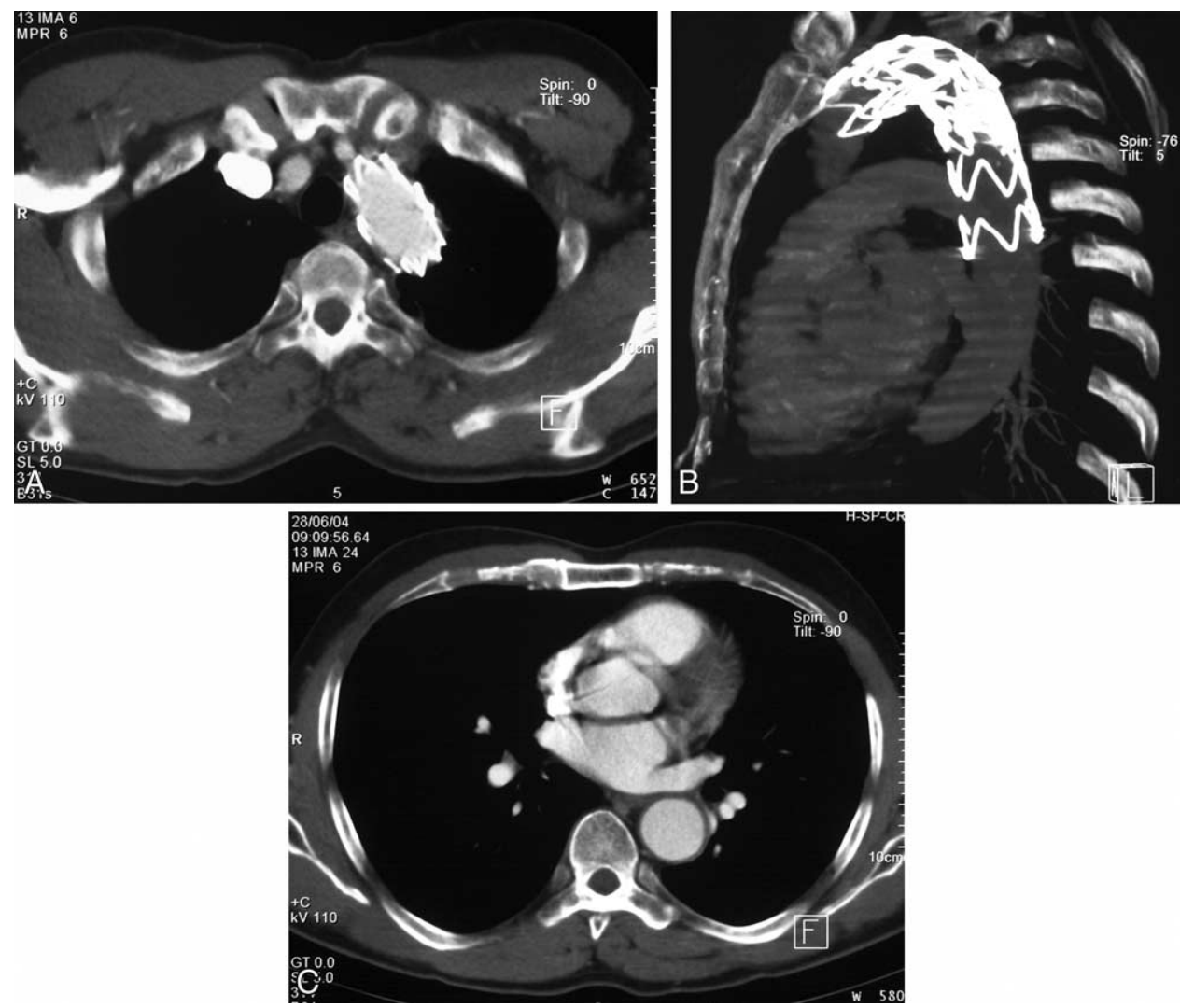

Figure 2. Follow-up CT after 12 months showing absence of ruptures, migrations, and endoleaks.

left subclavian artery, postcoarctation stenosis, and fraying of the posterior aspect of the aortic segment with aneurysmal dilatation distal to the subclavian artery (area of the aortobronchial fistula) (Figure 1,B).

A $30 \times 130$ Talent stent (Medtronic, Santa Rosa, Calif) was implanted in the aortic arch with fixation at the origin of the left subclavian artery. A baseline arteriogram revealed leakage in the aneurysmal dilatation. A proximal $30 \times 80$ Talent extension (Medtronic) was implanted. A baseline angiogram confirmed endovascular exclusion of the aneurysmal region, as well as absence of endoleaks (Figure 1,C).

On the fifth postoperative day, the patient had a new episode of massive hemoptysis requiring recovery measures. Angiography showed a minor filling of a space between the aortic wall and the stent because of inferior reentry. Selective catheterization of this area with a $5 \mathrm{~F}$ vertebral catheter and a Terumo (Tokyo, Japan) 0.35 guidewire revealed filling at the expense of right and left intercostal arteries and right bronchial arteries. Several coils 8 to $15 \mathrm{~mm}$ in diameter were released to seal this endoleak area. An immediate selective angiogram showed decreased filling of these arteries. The patient remained subsequently stable and did not have hemoptysis again at any time.

The CT performed at 4 weeks showed adequate placement of the stent with minimal distal leak and decreased endoleaks. No ruptures, migrations, or endoleaks were seen in the follow-up CT performed at 12 months (Figure 2). The patient is asymptomatic and has not had any new episodes of hemoptysis.

\section{Discussion}

Aortobronchial fistulas are an uncommon complication of surgery in the thoracic aorta. The possibility of an aortobronchial fistula should always be considered in patients with hemoptysis and a history of surgery in the thoracic aorta. The next step is documentation of the existence of an anastomotic aneurysm, for which CT is considered the best single diagnostic tool. CT is able to detect a pseudoaneurysm, periaortic hematoma, and consolidation in the adjacent pulmonary area. However, visualization of the aortobronchial fistula is only possible in $17 \%$ of cases. $^{1}$

Perioperative mortality with conventional surgical treatment exceeds $18 \%$ at 30 days for primary thoracic aortic aneurysms ${ }^{2}$ and is up to $41 \%$ when pseudoaneurysm exists. Postoperative morbidity is $42 \%$ and includes long-term mechanical ventilation, pneumonia, acute myocardial infarction, and paraplegia. $^{3}$

Endovascular repair in the thoracic aorta is less invasive and causes fewer cardiopulmonary (12\%), neurologic (3.7\%), renal $(5.5 \%)$, or spinal $(0 \%-12 \%)$ complications. ${ }^{4}$ Initial series reported a 30 -day mortality of approximately $10 \%,{ }^{5}$ but with the development of new prostheses and increased understanding and experi- 
ence in the procedure, the number of perioperative complications has gradually decreased.

To conclude, endovascular treatment for aortobronchial fistulas is technically feasible and is associated with higher survival than conventional surgery. Midterm results in regard to cessation of hemoptysis episodes are good. Specific complications, such as endoleaks or the need for adjuvant processes, have not been eliminated yet. Stent improvement and optimal patient management will most likely decrease these complications inherent to the method. A longer term follow-up is required to establish the results of these procedures. Prospective, randomized studies allowing for an analysis of the results and a comparison with the results of conventional surgery are difficult to conduct because of the low prevalence of the condition and the urgent solution required.

\section{References}

1. Miyata T, Ohara N, Shigematsu H, Konishi T, Yamaguchi H, Kazama S, et al. Endovascular stent graft repair of aortopulmonary fistula. $J$ Vasc Surg. 1999;29:557-60.

2. Leobon B, Roux D, Mugniot A, Rousseau H, Cérene A, Glock Y, et al. Endovascular treatment of thoracic aortic fistulas. Ann Thorac Surg. 2002;74:247-9.

3. Thompson CS, Ramaiah VG, Rodriguez-Lopez JA, Vranic M, Rajogopalan R, DiMugno L, et al. Endoluminal stent graft repair of aortobronchial fistulas. J Vasc Surg. 2002;35:387-91.

4. Neuhauser B, Perkmann R, Greiner A, Steingruber I, Tauscher T, Jaschke W, et al. Mid-term results after endovascular repair of the atherosclerotic descending thoracic aortic aneurysm. Eur J Vasc Endovasc Surg. 2004;28:146-53.

5. Orend KH, Scharrer-Pamler R, Kapfer X, Kotsis T, Görich J, SunderPlassmann L. Endovascular treatment in diseases of the descending thoracic aorta: 6-year results of a single center. J Vasc Surg. 2003;37: 91-9.

\title{
Monobloc aorto-mitral homograft or mechanical valve replacement: A new surgical option for extensive bivalvular endocarditis
}

\author{
J. F. Obadia, MD, PhD, ${ }^{a}$ R. Hénaine, MD, ${ }^{a}$ C. Bergerot, $M D,{ }^{b}$ I. Ginon, $M D,{ }^{b}$ P. Nataf, MD, ${ }^{c}$ N. Chavanis, $M D,{ }^{a}$ \\ J. Robin, MD, PhD, ${ }^{a}$ X. André-Fouët, MD, ${ }^{\text {b }}$ J. Ninet, MD, and O. Raisky, MD, PhD, ${ }^{a}$ Lyon and Saint Denis, France
}

A ortic and mitral prosthetic valve endocarditis with extensive abscess is generally considered to be a critical situation with no satisfactory technical solution. ${ }^{1,2}$ Although we respect the principle of wide resection proposed by Tirone David, ${ }^{3}$ we report a simplified reconstruction solution using an aorto-mitral monobloc.

\section{Technique}

The first step consists of wide resection including the aortic and mitral valve prostheses, the proximal aorta, and the aorto-mitral curtain. This resection leaves a single gaping aorto-mitral orifice and 2 button-shaped coronary ostia. The second step of reconstruction can be simplified, when it is planned, using either a monobloc aorto-mitral homograft (Figure 1), for which we have already

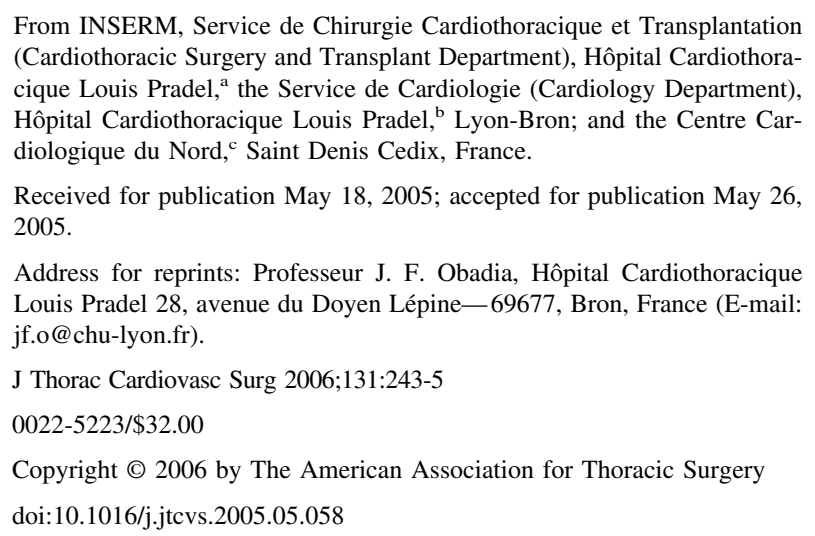

described the implantation technique, ${ }^{4}$ or a monobloc mechanical prosthesis prepared before starting cardiopulmonary bypass to limit the duration of the crossclamp time (Figure 2).

In both cases, an additional pericardial patch is necessary to reconstruct the roof of the left atrium, and the coronary ostia are reimplanted according to Bentall's technique.

\section{Patients}

Five patients aged 36 to 56 years underwent reoperation for the third to fifth time with extensive abscessing infectious endocarditis on aortic and mitral prostheses. One patient also had tricuspid extension with a ventricular septal defect. All 5 patients had severely altered hemodynamics and sepsis, and 3 of them were considered to be inoperable in another center before being referred to us. The microorganism isolated was Staphylococcus aureus in 2 cases, Candida glabrata in 1 case, Kingella dentrificans in 1 case, and Streptococcus sanguis in 1 case. The ejection fraction was always preserved $(>60 \%)$.

\section{Results}

Because of the availability of homografts in our tissue bank, 3 patients received an aorto-mitral homograft and the other 2 patients had to be treated by monobloc mechanical reconstruction. One patient also required placement of a tricuspid bioprosthesis and repair of an interventricular septal defect (mean crossclamp time: 186 minutes, mean cardiopulmonary bypass time: $231 \mathrm{~min}$ utes). All 5 patients recovered from the episode of endocarditis requiring surgery with satisfactory long-term echocardiographic follow-up of the reconstruction. However, 1 patient who was comatose on arrival in the operating room never recovered after 